\title{
Intramedullary central neurocytoma of the thoracic spinal cord: A case report and literature review
}

\author{
ZHIMIN LI, JUN GAO, TIANYU WANG, XIANGYI KONG, JIAN GUAN and YONGNING LI \\ Department of Neurosurgery, Peking Union Medical College Hospital, \\ Chinese Academy of Medical Sciences and Peking Union Medical College, Beijing 100730, P.R. China
}

Received September 13, 2017; Accepted December 12, 2017

DOI: $10.3892 /$ mco.2018.1570

\begin{abstract}
Central neurocytomas (CNs) are rare benign tumors located in the central nervous system with a good prognosis. These tumors are predominantly located in the lateral ventricle near the foramen of Monro or in the third ventricle. Similar tumors that are located outside the ventricle are also called extraventricular neurocytomas, and have an even lower morbidity. Until now, several tumors have been identified in the thalamus, cerebellum, pons, medulla oblongata and spinal cord. In total, 24 cases of neurocytomas located in the spinal cord have been reported in English journals. The present study reported a patient with an intramedullary central neurocytoma of the thoracic spinal cord, diagnosed from clinical features, imaging findings, pathology and immunohistochemistry. The present case report also outlined the prognosis of the patient and reviewed the literature currently available on CNs located in the spinal cord.
\end{abstract}

\section{Introduction}

Central neurocytomas (CNs) are rare neuronal tumors that predominantly appear in supratentorial ventricles in young adults and account for $0.1-0.5 \%$ of all intracranial tumors worldwide (1). In 1982, Hassoun et al (2) proposed the concept of pathological diagnosis of CNs for the first time. In 1992, Nishio et al (3) first reported the extraventricular neurocytoma (EVN), an even rarer tumor than CN. In 2000, the World Health Organization (WHO) central nervous system tumor classification listed $\mathrm{CN}$, which was considered as a neurogenic tumor that specially developed in the lateral ventricles or third ventricle with a good prognosis (4). However, since 2000 , various tumor cases with morphological and immuno-

Correspondence to: Professor Yongning Li, Department of Neurosurgery, Peking Union Medical College Hospital, Chinese Academy of Medical Sciences and Peking Union Medical College, Shuaifuyuan 1, Beijing 100730, P.R. China

E-mail: pumchliyn@hotmail.com

Key words: central neurocytoma, spinal cord tumor, extraventricular neurocytoma histochemical characteristics similar to those of $\mathrm{CN}$ but with a location outside of the ventricles have been reported (5-7). As a result, in 2007, WHO added EVN into the CNS tumor classification (8).

EVN are rarely located in the spinal cord, and only 24 cases of EVN in the spinal cord have been reported in English literatures. The present case report detailed a patient with an intramedullary $\mathrm{CN}$ of the thoracic spinal cord, and available literature was also summarized and reviewed.

\section{Case report}

A 50-year-old female was admitted to the Department of Neurosurgery of Peking Union Medical College Hospital (Beijing, China) in March 2014 with a history of lower back pain for 6 months and walking difficulty for half a month. At the same time, the patient also experienced zonesthesia at the epigastrium, bilateral lower extremity numbness and difficulty to place bilateral feet firmly on the ground.

According to the nervous system physical examination, the patient had bilateral lower extremity hypermyotonia. The muscle power of both lower extremities was evaluated as grade 4 , according to manual muscle testing (9). The needle sensation weakened from the level of the navel to the ankle. Furthermore, the topognosis and two-point discrimination also weakened. The abdominal reflex was not observed, while hyperfunction of bilateral patellar tendon reflex existed. The patient also demonstrated Babinski and Chaddock signs that were very weak.

Magnetic resonance imaging (MRI) indicated an intramedullary irregular lesion extending from the level of T5 to T12 vertebrae, which had a length of $17 \mathrm{~cm}$. The lesion showed iso/hypointense on T1-weighted images and iso/hyperintense on T2-weighted images. The margin was not very clear, making it difficult to distinguish the lesion from the normal spinal cord. Following an intravenous injection of gadolinium-diethylenetriamine pentaacetic acid (Gd-DTPA; Bayer AG, Leverkusen, Germany) at a dosage of $0.1 \mathrm{mmol} / \mathrm{kg}$, the lesion showed intense heterogeneous enhancement of the solid part and non-enhancement of the cystic part. As demonstrated in Fig. 1, a long strip and cotton-shaped intramedullary segment showed up as hyperintense on T2-weighted images and non-enhancement was demonstrated following the administration of Gd-DTPA, which was considered as a syringomyelia 
caused by abnormal hydrodynamics of the cerebrospinal fluid (Fig. 1A and B).

The patient underwent a posterior approach laminectomy from the level of T5-T10. It was observed that the spinal dura mater was tense and so an incision was made on the dura lengthways. The spinal cord from the T5-T10 segment was obviously thickened and the pulses of the cerebrospinal fluid were not observed. An incision was made along the posterior median fissure of the spinal cord and it was revealed that the thickness of the dorsal part of the spinal cord was $\sim 4 \mathrm{~mm}$. The tumor was dark red with an abundant blood supply, with completely soft tissue characteristics. There was an unclear margin between the tumor and the normal spinal cord. Additionally, a yellow transparent liquid was observed flowing out of the cystic part of the tumor beside the solid part of the tumor when the cystic part was explored. As it was not possible for the tumor to be totally removed, $80 \%$ of the tumor was resected for the purpose of decompression. Following resection, the pulses of cerebrospinal fluid were observed prior to suturing of the incision.

Following resection, tumor tissues were immersed in $4 \%$ paraformaldehyde (PFA) for $4 \mathrm{~h}$ at $4^{\circ} \mathrm{C}$ and transferred to $70 \%$ ethanol for $2 \mathrm{~h}$ at $4^{\circ} \mathrm{C}$. The tissues were placed in processing cassettes, dehydrated through a serial alcohol gradient $(85 \%$ ethanol for $2 \mathrm{~h}, 95 \%$ ethanol for $1.5 \mathrm{~h}, 100 \%$ ethanol for $30 \mathrm{~min}$ at room temperature), and embedded in paraffin wax blocks. Following this, $5-\mu \mathrm{m}$-thick tumor tissue sections were dewaxed in xylene, rehydrated through decreasing concentrations of ethanol (95\% ethanol for $2 \mathrm{~min}, 85 \%$ ethanol for $2 \mathrm{~min}, 75 \%$ ethanol for $2 \mathrm{~min}$ at room temperature), and washed in PBS. Subsequently, the sections were stained with hematoxylin and eosin $(\mathrm{H} \& \mathrm{E})$ for $10 \mathrm{~min}$ at room temperature. Following staining, sections were dehydrated through increasing content ratios of ethanol (70\% ethanol for $2 \mathrm{~min}, 85 \%$ ethanol for $2 \mathrm{~min}, 95 \%$ ethanol for $2 \mathrm{~min}$ at room temperature) and xylene for $2 \mathrm{~min}$ at room temperature. A light microscope was used to observe the tissue sections with magnifications of x100 and x400. Histopathologically, microscopic examination using $\mathrm{H} \& \mathrm{E}$ staining revealed that the tumor consisted of small, round uniform cells with perinuclear halos, with similar cellular structures to those observed in oligodendrogliomas. The tumor cells had finely speckled nuclei and branched blood capillaries.

For immunohistochemistry, tissues were fixed in 4\% PFA overnight at $4^{\circ} \mathrm{C}$ and cryoprotected with $30 \%$ sucrose saturation. Tissues were sectioned to $5-\mu \mathrm{m}$ thickness and stored at $-80^{\circ} \mathrm{C}$ for subsequent use. The PFA-fixed tumor tissue sections were thawed for 20-30 sec and rinsed with PBS. Endogenous peroxidase activity was blocked using $6 \% \mathrm{H}_{2} \mathrm{O}_{2}$ in $80 \%$ methanol for $10 \mathrm{~min}$ at room temperature. The tissue sections were then blocked with $2 \%$ normal goat serum (Abcam, Cambridge, UK) for $30 \mathrm{~min}$ at room temperature and incubated with a rabbit anti-human monoclonal antibody (1:250 in blocking buffer; cat. no. ab68428; Abcam, Cambridge, UK) for $2 \mathrm{~h}$ at room temperature, washed with PBS three times (10 min each), and incubated with a goat anti-rabbit biotinylated antibody (1:1,000 in blocking buffer; cat. no. ab7090; Abcam, Cambridge, UK) for $1 \mathrm{~h}$ at room temperature. The slides were washed again with PBS three times (10 min each), and immunodetection was performed using a VECTASTAIN Elite ABC system (Vector Laboratories, Inc., Burlingame, CA, USA) and with 3,3'-diaminobenzidine as

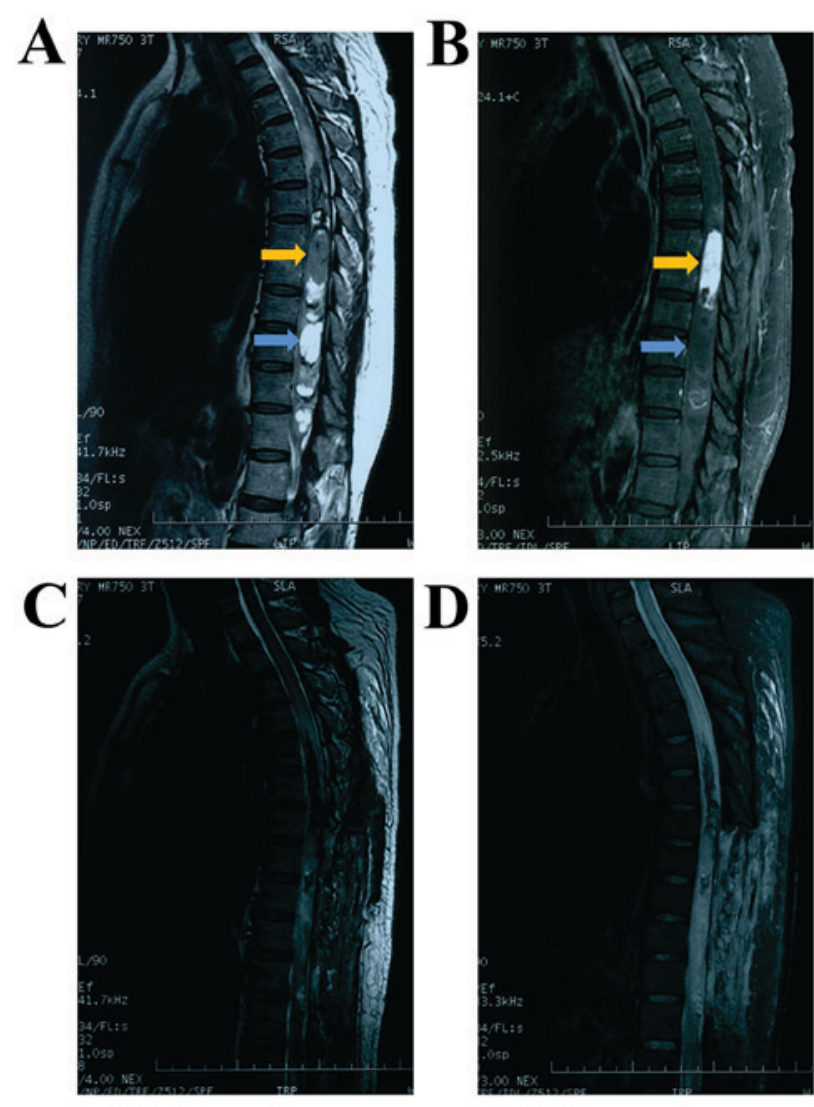

Figure 1. MRI results. (A) Pre-operative MRI demonstrated that the lesion was iso/hyperintense on T2-weighted images. The margin was not very clear to distinguish the lesion from the normal spinal cord. The yellow arrow indicates the solid part of the tumor and the blue arrow indicates the cystic part of the tumor. (B) Following injection of gadolinium-diethylenetriamine pentaacetic acid, the lesion demonstrated intense heterogeneous enhancement of the solid part (yellow arrow) and non-enhancement of the cystic part (blue arrow). (C) Post-operative MRI indicated that the lesion was iso/hypointense on T1-weighted images. (D) T2-weighted images demonstrated that the volume of the solid part was reduced and a cyst was located in the spinal cord. MRI, magnetic resonance imaging.

a substrate. Light microscopy was used to observe the tissue sections with a magnification of $\mathrm{x} 400$. The immunohistochemical examination demonstrated that the tumor cells were positive for NeuN, Oligo-2, synaptophysin (Syn) and cluster of differentiation 34 protein in blood vessels; however, the tumor cells were negative for glial fibrillary acidic protein (GFAP) and epithelial membrane antigen. Furthermore, the Ki-67 index was $<1 \%$ (Fig. 2). These results, particularly those of the immunohistochemistry analysis, directed to the diagnosis of EVN according to the 2016 World Health Organization Classification of Tumors of the Central Nervous System (10).

The patient's postoperative recovery was satisfactory with rehabilitation training, and the patient was able to walk for 20 min with the help of others 1 year following surgery. The patient had to rely on a wheelchair prior to surgery. Radiotherapy of 45 Gy was performed 1 month after surgery and patient follow up was conducted every 12 months for 36 months. The latest postoperative MRI indicated that the tumor had no recurrence or metastasis (Fig. 1C and D). Written informed consent was provided by the patient prior to publication of the present case report. 


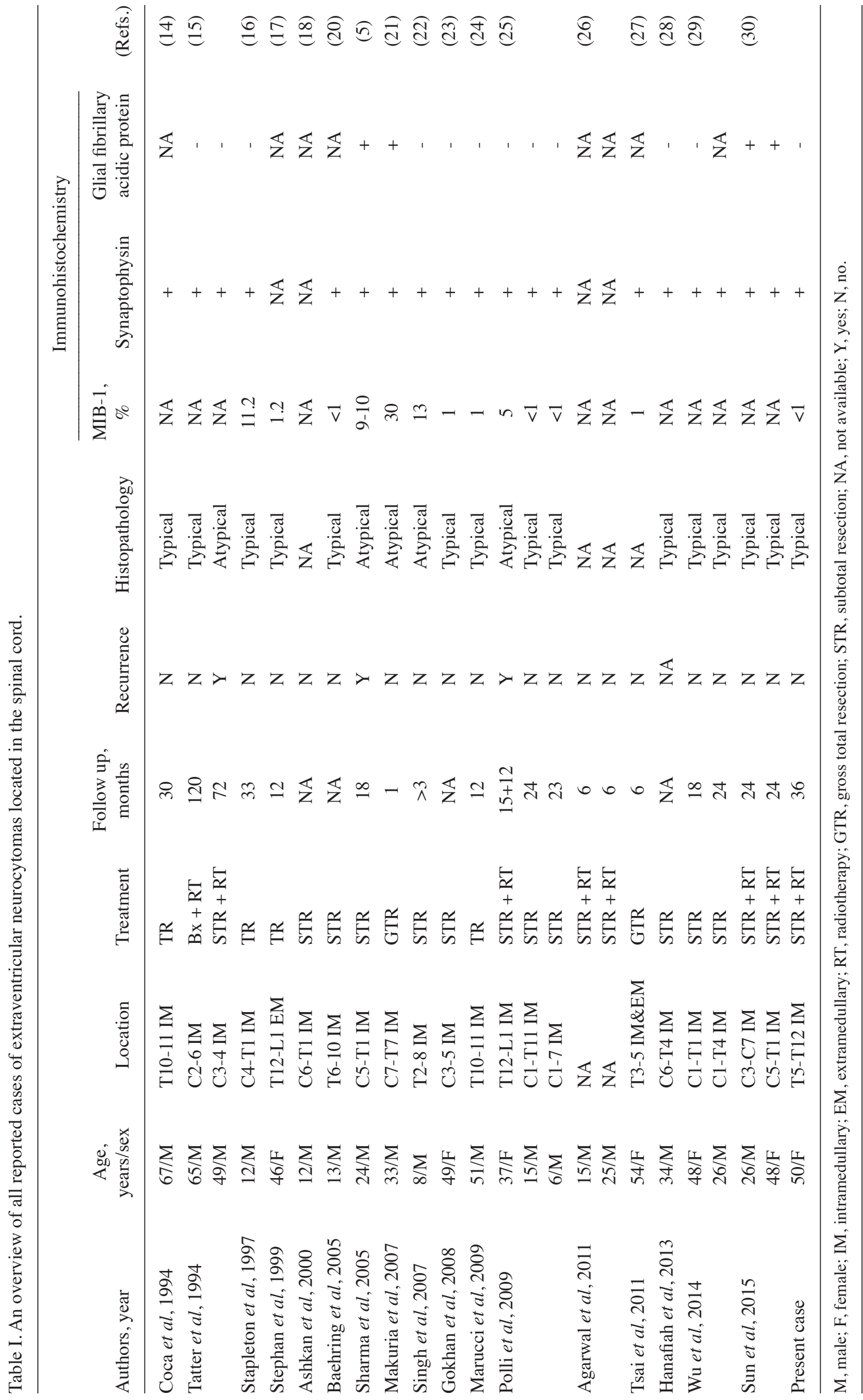



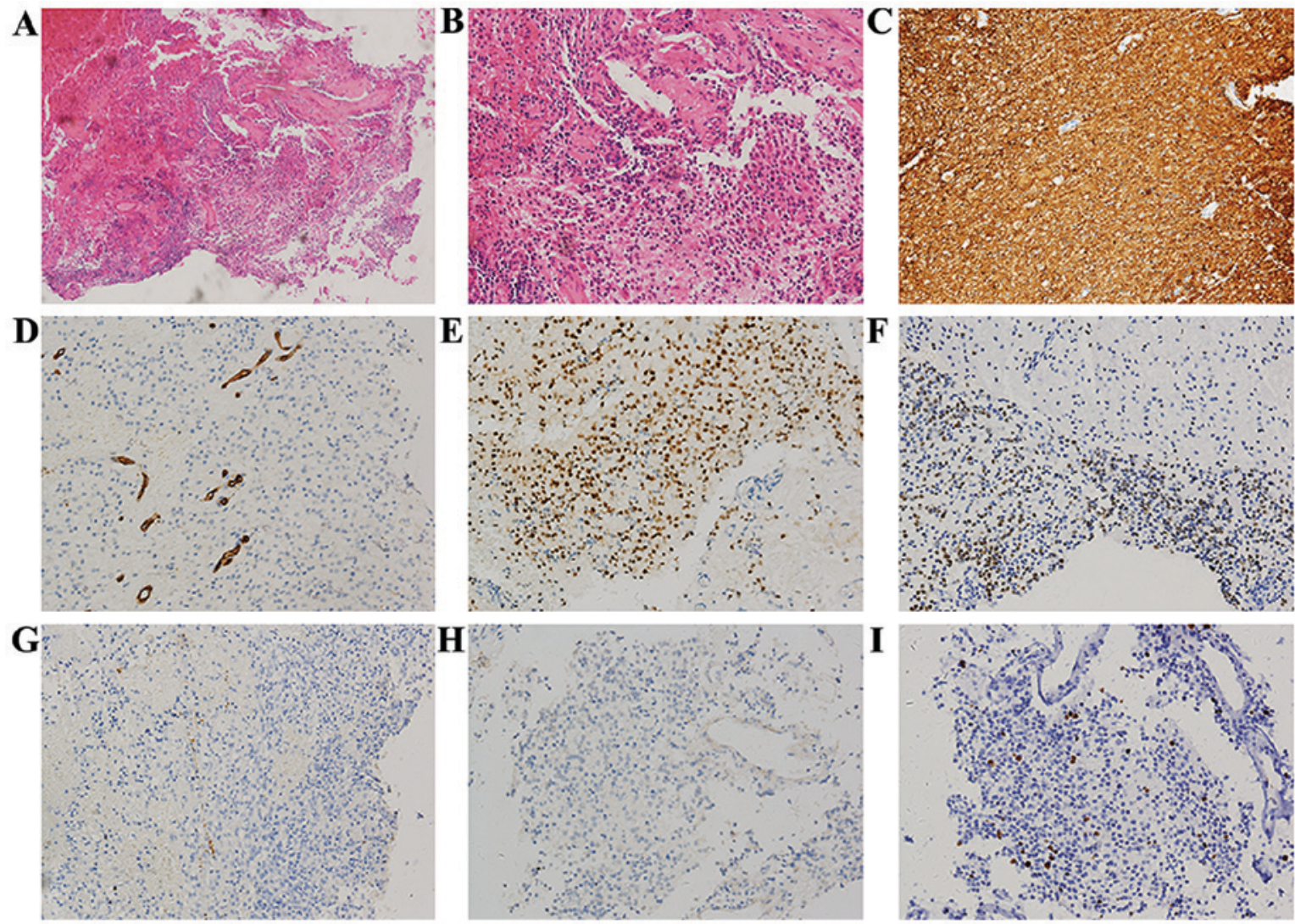

Figure 2. H\&E staining and immunohistochemistry results. (A and B) H\&E staining revealed that the tumor consisted of small, round uniform cells with perinuclear halos. The tumor cells had finely speckled nuclei and branched blood capillaries [(A) magnification x100; (B) magnification x400]. The immunohistochemistry examination indicated that the tumor cells were positive for (C) synaptophysin, (D) cluster of differentiation 34, (E) NeuN and (F) Oligo-2. Brown coloration indicates positive staining. However, the tumor cells were negative for $(\mathrm{G})$ glial fibrillary acidic protein and $(\mathrm{H})$ epithelial membrane antigen. (I) The Ki-67 index was $<1 \%$. C-I, magnification x400. H\&E, hematoxylin and eosin.

\section{Discussion}

EVN has similar characteristics to $\mathrm{CN}$ in terms of histology, pathology and immunohistochemistry; however, EVNs are not located within the ventricles (1). In addition to the cerebrum, EVNs have also been reported in the thalamus (11), the pons (12), the cerebellum (13) and the spinal cord (5). It is extremely rare for EVNs to develop in the spinal cord. Until now, a total of only 24 cases identified in the spinal cord had been reported in English literatures (5,14-30). These cases are summarized in Table I.

Of the 25 cases presented in Table I, 18 cases were male and 7 cases were female, with a sex ratio of 2.57: 1 . The youngest patient was 6-years old and the oldest patient was 67-years old. However, the number of cases of spinal cord CN is too small to illustrate whether the development of the tumor is associated with age or gender. In terms of the location of the tumor, the literature revealed that these tumors are more likely to be located at the cervical or thoracic spinal cord, and the majority of the tumors are intramedullary tumors.

The clinical signs or symptoms are very similar to other intramedullary tumors and the symptoms may last for several months or years as the neurocytomas grow slowly. Furthermore, MRI characteristics are variable and sometimes it is not possible to distinguish EVNs clearly from other intramedullary tumors. The signals of primary spinal cord neurocytomas may be iso/hypointense on T1-weighted images and iso/hyperintense on T2-weighted images. The tumor may show heterogeneous enhancement following the administration of Gd-DTPA. At both ends of the tumor, syringomyelia is identified in the majority of cases $(5,15,19)$. These characteristics are very similar to ependymomas and oligodendrogliomas, which makes it difficult to make a definite diagnosis only through the use of MRI. Therefore, it is necessary to use histopathology and immunohistochemistry features in order to make an accurate diagnosis of a spinal cord neurocytoma.

The differential diagnoses of spinal cord neurocytomas are intramedullary tumors, particularly the ependymoma and oligodendroglioma. The neurocytomas have a fine neuropil-like fibrillary matrix, while the ependymomas have a coarser glial fibrillary matrix (22). Neurocytomas are composed of small round cells, which have a slightly eosinophilic cytoplasm with clear perinuclear halos; this is very similar to oliodendrogliomas (5). Immunohistochemistry is necessary for differential diagnosis. Neurocytomas are immunopositive for Syn, which is considered the most reliable immunomarker for the diagnosis of neurocytoma $(8,31)$. Additionally, in the present case, GFAP immunohistochemical staining was negative and the Syn immunohistochemical staining was positive, which suggested that the tumor originated from the nerve cells. These histopathology and immunohistochemistry features helped to make a definite diagnosis of spinal cord neurocytoma in the present case. Furthermore, according to the limited data from the literature review, it may be hypothesized 
that the recurrence rate of the tumor is more closely related to the histologic atypia and high MIB-1 labeling index. This hypothesis is similar with the view of Sharma et al (5).

Gross total resection is advised to ensure the best possible prognosis and to avoid recurrence. However, sometimes the tumor margin is not clear and it is difficult to distinguish between the normal spinal cord and the segments of the spinal cord that are involved. Therefore, subtotal resection may be a better choice to protect the normal tissue of the spinal cord. By reviewing the literature, 18 of the 25 cases (72\%) underwent subtotal resection of the tumor, and 7 of the $18(39 \%)$ that received subtotal resection also received radiotherapy following surgery.

The use of radiotherapy following subtotal resection remains to be under debate, as there is no guideline available to aid in the determination of whether or not radiotherapy should be used. Stapleton et al (16) suggested that postoperative radiotherapy should be avoided, particularly in young patients, as the tumor tends to show benign clinical behavior. However, Martin et al (19) considered that radiotherapy may delay progression and protect against recurrences following subtotal resection, thus arguing that it should be used on residual or recurrent cases with consideration of the side effects. Although chemotherapy has been demonstrated to be effective in patients with CN $(32,33)$, it has not yet been used on spinal cord neurocytoma, and more cases are required to fully evaluate its effectiveness.

\section{Acknowledgments}

We would like to thank Dr Xiaolong Liang (Department of Pathology, Peking Union Medical College Hospital, Chinese Academy of Medical Sciences and Peking Union Medical College, Beijing, China) who provided clinical support and clinical examination.

\section{References}

1. Sharma MC, Deb P, Sharma S and Sarkar C: Neurocytoma: A comprehensive review. Neurosurg Rev 29: 270-285, 2006.

2. Hassoun J, Gambarelli D, Grisoli F, Pellet W, Salamon G, Pellissier JF and Toga M: Central neurocytoma. An electron-microscopic study of two cases. Acta Neuropathol 56: 151-156, 1982.

3. Nishio S, Takeshita I, Kaneko Y and Fukui M: Cerebral neurocytoma. A new subset of benign neuronal tumors of the cerebrum. Cancer 70: 529-537, 1992.

4. Kleihues P, Louis DN, Scheithauer BW, Rorke LB, Reifenberger G, Burger PC and Cavenee WK: The WHO classification of tumors of the nervous system. J Neuropathol Exp Neurol 61: 215-225, 2002.

5. Sharma S, Sarkar C, Gaikwad S, Suri A and Sharma MC: Primary neurocytoma of the spinal cord: A case report and review of literature. J Neurooncol 74: 47-52, 2005.

6. Kowalski RJ, Prayson RA and Lee JH: Skull base neurocytoma: Case report and review of the literature of extraventricular neurocytomas. Skull Base 12: 59-65, 2002.

7. Brat DJ, Scheithauer BW, Eberhart CG and Burger PC: Extraventricular neurocytomas: Pathologic features and clinical outcome. Am J Surg Pathol 25: 1252-1260, 2001.

8. Louis DN, Ohgaki H, Wiestler OD, Cavenee WK, Burger PC, Jouvet A, Scheithauer BW and Kleihues P: The 2007 WHO classification of tumours of the central nervous system. Acta Neuropathol 114: 97-109, 2007.

9. Conable KM and Rosner AL: A narrative review of manual muscle testing and implications for muscle testing research. J Chiropr Med 10: 157-165, 2011.
10. Louis DN, Perry A, Reifenberger G, von Deimling A Figarella-Branger D, Cavenee WK, Ohgaki H, Wiestler OD, Kleihues P and Ellison DW: The 2016 World Health Organization Classification of Tumors of the central nervous system: A summary. Acta Neuropathol 131: 803-820, 2016.

11. Cheung YK: Central neurocytoma occurring in the thalamus: CT and MRI findings. Australas Radiol 40: 182-184, 1996.

12. Swinson BM, Friedman WA and Yachnis AT: Pontine atypical neurocytoma: Case report. Neurosurgery 58: E990, 2006.

13. Ogiwara H, Dubner S, Bigio E and Chandler J: Neurocytoma of the cerebellum. Surg Neurol Int 2: 36, 2011.

14. Coca S, Moreno M, Martos JA, Rodriguez J, Barcena A and Vaquero J: Neurocytoma of spinal cord. Acta Neuropathol 87: 537-540, 1994.

15. Tatter SB, Borges LF and Louis DN: Central neurocytomas of the cervical spinal cord. Report of two cases. J Neurosurg 81: 288-293, 1994.

16. Stapleton SR, David KM, Harkness WF and Harding BN: Central neurocytoma of the cervical spinal cord. J Neurol Neurosurg Psychiatry 63: 119, 1997.

17. Stephan CL, Kepes JJ, Arnold P, Green KD and Chamberlin F: Neurocytoma of the cauda equina. Case report. J Neurosurg 90 (2 Suppl): S247-S251, 1999.

18. Ashkan K, Casey AT, D'Arrigo C, Harkness WF and Thomas DG: Benign central neurocytoma. Cancer 89: 1111-1120, 2000.

19. Martin AJ, Sharr MM, Teddy PJ, Gardner BP and Robinson SF: Neurocytoma of the thoracic spinal cord. Acta Neurochir (Wien) 144: 823-828, 2002.

20. Baehring J, Ogle E, Sze G, Duncan C and Bannykh S: Ganglioneurocytoma of the spinal cord. J Neurooncol 71: 149, 2005.

21. Makuria AT, Henderson FC, Rushing EJ, Hartmann DP, Azumi N and Ozdemirli M: Oligodendroglioma with neurocytic differentiation versus atypical extraventricular neurocytoma: A case report of unusual pathologic findings of a spinal cord tumor. J Neurooncol 82: 199-205, 2007.

22. Singh A, Chand K, Singh H, Sarkar C and Sharma MC: Atypical neurocytoma of the spinal cord in a young child. Childs Nerv Syst 23: 207-211, 2007.

23. Gokhan GA, Gurer IE, Akyuz M and Tuncer R: A case of extraventricular neurocytoma of the spinal cord. Neuropathology 28: 322-325, 2008.

24. Marucci G, Barbanera A, Serchi E and Andreoli A: Ganglioneurocytoma of the spinal cord: Report of a case and review of literature. Eur Spine J 18 (Suppl 2): S183-S185, 2009.

25. Polli FM, Salvati M, Miscusi M, Delfini R and Giangaspero F: Neurocytoma of the spinal cord: Report of three cases and review of the literature. Acta Neurochir (Wien) 151: 569-574, 2009.

26. Agarwal S, Sharma MC, Sarkar C, Suri V, Jain A, Sharma MS, Ailawadhi P, Garg A and Mallick S: Extraventricular neurocytomas: A morphological and histogenetic consideration. A study of six cases. Pathology 43: 327-334, 2011.

27. Tsai CY, Tsai TH, Lin CH, Cheng YH and Lieu AS: Unusual exophytic neurocytoma of thoracic spine mimicking meningioma: A case report and review of the literature. Eur Spine J 20 (Suppl 2): S239-S242, 2011.

28. Hanafiah M, Low SF, Sridharan R and Young B: Spinal neurocytoma with extensive syringohydromyelia. BMJ Case Rep 2013: pii: bcr2013201285, 2013.

29. Wu L, Deng X, Yang C, Zhao L, Yang T and Xu Y: Primary spinal neurocytoma involving the medulla oblongata: Two case reports and a literature review. Neurol Med Chir (Tokyo) 54: 417-422, 2014.

30. Sun Z, Yuan D, Cui Z, Sun Y, Yang J, Yan P and Zuo H: Intramedullary neurocytomas in the craniocervical spinal cord: A report of two cases and a literature review. Oncol Lett 9: 86-90, 2015.

31. Quinn B: Synaptophysin staining in normal brain: Importance for diagnosis of ganglioglioma. Am J Surg Pathol 22: 550-556, 1998.

32. Dodds D, Nonis J, Mehta M and Rampling R: Central neurocytoma: A clinical study of response to chemotherapy. J Neurooncol 34: 279-283, 1997.

33. Brandes AA, Amistà P, Gardiman M, Volpin L, Danieli D, Guglielmi B, Carollo C, Pinna G, Turazzi S and Monfardini S: Chemotherapy in patients with recurrent and progressive central neurocytoma. Cancer 88: 169-174, 2000.

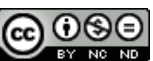

This work is licensed under a Creative Commons Attribution-NonCommercial-NoDerivatives 4.0 International (CC BY-NC-ND 4.0) License. 